A Publication of the Systems \& Psychosocial Advances Research Center (formerly the Center for Mental Health Services Research) A Massachusetts Department of Mental Health Research Center of Excellence

Volume 11

Issue 2

2014

\title{
Navigating the Complexity of Using Research in Policy and Practice Decisions
}

\author{
Susan Maciolek, Kathleen Biebel, Laurel Leslie, Gifty Debordes-Jackson, Joanne Nicholson
}

$\mathrm{C}$ alls to bridge the gap between "what is known" and "what is done" have led to a small but growing body of literature on how research is used in policy and practice decisionmaking. Early models of research use focused on the autonomous production and passive transfer of research, describing linear, rational processes whereby research is conducted by a research "producer" and then "pushed" to a ready and waiting research "user" (Lavis, Robertson, Woodside, Mcleod, \& Abelson, 2003). More recently, knowledge translation and exchange models have been promoted as potentially useful for examining the interactions among researchers, policymakers, and practitioners.

There are several themes common among a variety of knowledge translation and exchange models. First, researcher, practitioner, and policymaker communities all have knowledge and expertise that is needed by the other. Second, the knowledge being exchanged does not consist only of the available research about an evidence-based practice but also includes experiential knowledge about the context within which a policy or practice might be embedded (Graham et al., 2006). Third, relationships and trust among researchers, policymakers, and practitioners are critical (Gagnon, 2011; Ko, Kirsch, \& King, 2005). Last, knowledge translation and exchange models acknowledge the complexities of the sociopolitical context in which practice and policy decision-making occurs (Gibbons, 2008).

\section{The Context: The Massachusetts Children's Behavioral Health System Changes in the Massachusetts children's behavioral health system over the last decade presented a unique opportunity to examine}

knowledge exchange in a real-world setting. In 2006, Massachusetts was found in violation of the Federal Early Periodic Screening Diagnosis and Treatment (EPSDT) provisions of the Medicaid Act (Rosie D. v. Romney). A remedy plan was developed to enable eligible children with behavioral health issues to receive appropriate treatment and care in their homes and local communities.

Investigators examined the use of research evidence as state-level stakeholders prepared for and implemented court-mandated changes in children's behavioral health services in partnership with community agencies across the state. The study used mixed methods including an extensive review of public documents, an agency survey, and one-on-one and group interviews with key informants. ${ }^{i}$

\section{Multiple Levels and Episodes of Decision-Making}

The overarching goal of improving behavioral health services for Massachusetts children covered by Medicaid falls under the purview of Federal, state, and community-based entities. Decisions and actions at the Federal, state, and community levels are all necessary; no one level is sufficient by itself to change publicly funded behavioral health services for children. Decisions across these levels occurred over several years in three distinct episodes. Each episode had a different purpose, requiring the exchange of different types of knowledge and involving multiple and shifting participants representing research as well as policy, program, and practice.

- Episode 1: The Federal Court determined that the state had failed to comply with Federal EPSDT requirements and ordered a remedial plan with several components. To do so, the judge heard testimony from a range of 
researchers, clinicians, program administrators, family members, and fiscal experts.

- $\quad$ Episode 2: State administrators determined how to translate the remedy plan into state Medicaid program standards. They supplemented research knowledge provided by national experts with their own professional experience, the experience of administrators in other states that had made similar changes, and parents' experiences as conveyed by advocates.

- Episode 3: Community Service Agencies (CSAs) made daily practice decisions about how to implement Wraparound using the resources available in their communities and within Medicaid rules and rates. They relied on their own expertise and experience in delivering services as well as knowledge provided by a Wraparound purveyor and technical assistance teams from Medicaid's managed care entities.

\section{Decision-Making Parameters Narrow and Participants Broaden over Time}

Over the course of the three episodes, decisions made in one episode established parameters within which decisions in subsequent episodes had to be made. The Judge's ruling regarding EPSDT compliance and the resulting remedy plan became the parameter within which numerous decisions were made about revisions to state Medicaid program standards. The state Medicaid standards shaped and bounded the daily practice decisions by CSAs. Each of these decision episodes limited the range of choices available in subsequent episodes.

At the same time that the parameters narrowed in scope, the numbers of participants with different organizational affiliations increased. In the first episode, the Judge was the sole arbiter of the evidence and decision maker. Following his rulings, decision-making shifted to a small group of state administrators, with the input of plaintiff's attorneys and the court monitor. Once their decisions were translated into Medicaid program standards, decision-making shifted to the CSAs whose staff made practice decisions on a daily basis.

Thus, the nature of the complexity shifted from a broad policy question in the hands of one person to detailed program standards being interpreted by hundreds of practitioners. Researchers engaging in knowledge exchange must be aware of and prepared to navigate this shift to help maintain the integrity of research evidence as it is translated across inter-connected decision-making episodes.

\section{Public Documents}

Most participants were not consistently engaged across all three decision-making episodes, requiring some other vehicle for transmitting information. Public documents were essential to maintaining coherence from one set of decisions to the next. Both episodes two and three were guided by written documents resulting from decisions made during previous episodes. These documents established a public record readily available on web sites that allowed participants to learn about and track the basis of decisions from policy to program to practice.

\section{Intermediaries}

As the number of participants in the episodes broadened, so did the contextual factors informing or influencing their decision-making. Intermediaries were critical in translating both the complex context (e.g., regulatory, fiscal, and local community environment) and the research evidence (e.g., Wraparound). To be effective, intermediaries had to be knowledgeable about the research being embedded as well the state and local contexts. For more on the role of intermediaries in this case study, see Psychiatry Information in Brief, volume 10, issue 4.

Preliminary findings from this study call for heightened attention to the shifting and multi-dimensional complexity of decision-making that occurs in public service systems. Attention to this complexity will allow for the use of research evidence in coherent, relevant and effective ways.

Investigators: Joanne Nicholson, PhD (Dartmouth); Laurel K. Leslie, MD, MPH (Tufts); Susan Maciolek, MPP (Policy \& Management Consultant); Kathleen Biebel, PhD (UMMS); \& Gifty Debordes-Jackson, MA (UMMS) Funder: The William T Grant Foundation Time Period: July 2010 to June 2013 Contact: Joanne.Nicholson@Dartmouth.edu

${ }^{i}$ More detail about this study can be found at Leslie, L, Maciolek, S., Biebel, K., Debordes-Jackson, G. \& Nicholson, J. (in press). Exploring research use at the research-policy-practice interface in children's behavioral health services. Administration and Policy in Mental Health and Mental Health Services Research (2014). 


\section{References}

Gagnon, M. L. (2011). Moving knowledge to action through dissemination and exchange. Journal of Clinical Epidemiology, 64(1), 25-31.

Gibbons, M. (2008). Why is knowledge translation important?: Grounding the conversation. Focus: Technical Brief, 21. Retrieved from http://www.uofaweb.ualberta.ca/kusp/pdfs/CalgaryCIHR41.pdf

Graham, I. D., Logan, J., Harrison, M. B., Straus, S. E., Tetroe, J. M., Caswell, W., \& Robinson, N. (2006). Lost in knowledge translation: Time for a map? The Journal of Continuing Education in the Health Professions, 26(1), 13-24.

Ko, D. G., Kirsch, L., \& King, W. (2005). Antecedents of knowledge transfer from consultants to clients in enterprise system implementations. Management Information Systems Quarterly, 29(1).

Lavis, J. N., Robertson, D., Woodside, J. M., Mcleod, C. B., \& Abelson, J. (2003). How can research organizations more effectively transfer research knowledge to decision makers? Milbank Quarterly, 81(2), 221-248.

Rosie D. v. Romney, 410 F.Supp.2d 18. (2006). Retrieved from http://www.clearinghouse.net/chDocs/public/MHMA-0005-0012.pdf

Using Research in Policy and Practice Decisions - S. Maciolek, K. Biebel, L. Leslie, G. Debordes-Jackson, \& J. Nicholson 